\title{
Modified open-door cervical expansive laminoplasty for spondylotic myelopathy: operative technique, outcome, and predictors for gait improvement
}

Thomas T. Lee, M.D., Glen R. Manzano, B.S., and Barth A. Green, M.D.

Department of Neurological Surgery, University of Miami School of Medicine, Miami, Florida

Twenty-five patients underwent an expansive cervical laminoplasty for nontraumatic cervical spondylosis with myelopathy during the period from June 1990 to November 1994, and all had a minimum of 18 months of follow-up review. The open-door laminoplasty procedure presently reported consisted of the same approach evaluated by Hirabayashi in 1977, except that the authors of this report used three rib allografts to anchor the "open door," rather than spinous process sutures or autologous bone grafts. Posterior foraminotomies and decompression were performed in patients with clinical radiculopathy and radiographic evidence of foraminal stenosis.

Preoperatively, gait disturbance was present in all patients. All 25 patients (100\%) had long-tract signs on presentation. Nondermatomal upper-extremity symptoms (numbness, tingling, weakness, and pain) were quite common in this group of patients. Bowel, bladder, and/or sexual dysfunction was found in 13 (52\%) of 25 patients. Preoperative radiographic studies showed a mean midline anteroposterior diameter spinal canal/vertebral body (SC/VB) ratio of 0.623 and a mean compression ratio (sagittal/lateral diameter ratio $\mathrm{X} 100 \%)$ of $37 \%$.

This procedure was quite successful in relieving preoperative symptoms and few complications occurred. Gait disturbance was improved in $21(84 \%)$ of 25 patients and hand numbness and tingling were improved in 13 (87\%) of 15 patients. Bowel or bladder function improved in 10 (77\%) of 13 patients. Radiculopathy, when present, was alleviated in all four patients after the decompressive procedure. The postoperative SC/VB ratio, as measured by plain lateral radiographs and/or computerized tomography scans, was improved to 0.871 , a $38 \%$ improvement. In a comparison with the preoperative SC/VB ratio using the two-tailed t-test, alpha was less than 0.001 . The compression ratio improved to $63 \%$ postoperatively, which yielded an alpha less than 0.005 according to the two-tailed t-test. Only one postoperative complication, an anterior scalene syndrome, was encountered.

Various predictors of surgical outcome based on gait improvement were evaluated. Age greater than 60 years at the time of presentation, duration of symptoms more than 18 months prior to surgery,

preoperative bowel or bladder dysfunction, and lower-extremity dysfunction were found to be associated with poorer surgical outcome. Even when these conditions were present, gait improvement was noted in at least $70 \%$ of the patients.

Key Words * cervical spondylotic myelopathy * expansive laminoplasty * gait improvement 
Cervical spondylotic myelopathy results from the degenerative process of the vertebral column and associated soft tissue structures. The end product is cervical canal stenosis and spinal cord compression and subsequent injury. Epstein[5] reported the natural history of 1355 patients who underwent conservative (nonsurgical) treatment, showing a $64 \%$ nonimprovement rate. Of these $64 \%$ of patients $26 \%$ displayed neurological deterioration. Other investigators[3] have found a much higher rate of clinical deterioration and nonimprovement in their patient group.

Two general approaches for the surgical treatment of cervical spondylotic myelopathy have been used: anterior[15] and posterior. The anterior approach consists of an anterior decompression coupled with a strut graft fusion with or without instrumentation.[15] This approach is feasible and safe for up to three vertebral segments, $[1,17]$ although other authors have advocated anterior decompression for only one or two vertebral segments. $[14,16]$ Posterior decompression can be achieved using either a laminectomy or a laminoplasty.[7,12] Because laminectomies have been reported to cause postoperative instability, kyphotic deformity, and postlaminectomy membrane, $[5,11]$ we use the open-door laminoplasty technique for the treatment of cervical spondylotic myelopathy.

Cervical laminoplasty was developed by surgeons in Japan after a high incidence of postlaminectomy deformity was encountered. Oyama, et al.,[10] described the expansive Z-laminoplasty, which was subsequently modified by Hirabayashi in 1977 to an open-door expansive laminoplasty.[7] The role of laminoplasty for the ossification of the posterior longitudinal ligament (OPLL) has been well established in the past,[5] even though some authors still maintained that the anterior approach was the preferred treatment. Laminoplasty has been demonstrated to be safe and to have fairly good long-term results.[12] However, the outcome of laminoplasty for the treatment of cervical spondylosis is not as well defined. Hirabayashi and Satomi[7] reported 35 cases of laminoplasty performed to treat cervical stenosis and multilevel spondylosis, with $54 \%$ of the patients having more than a $50 \%$ recovery rate. The long-term canal patency rate was reported to be high.[7,12]

We present a series of 25 consecutive patients who underwent open-door expansive laminoplasty for spondylotic myelopathy. This series excluded laminoplasties performed for early posttraumatic decompression, OPLL, and for cervical spinal cord tumor resection performed at our institution. The preoperative presenting signs and symptoms are reported and compared to their postoperative symptomatology. Various predictors of surgical outcome (based here on gait improvement) were evaluated. Operative techniques are reported as well.

\section{CLINICAL MATERIAL AND METHODS}

\section{Patient Population}

Twenty-five patients underwent an open-door laminoplasty for cervical spondylotic myelopathy performed at our institution by the senior author (B.A.G.) between June 1990 and November 1994. All patients received a comprehensive preoperative evaluation at which time it was ascertained that they had failed to improve following conservative trials with cervical collar, physiotherapy, and nonsteroidal antiinflammatory medication and continued to show progression of their symptoms. Preoperative radiographic studies consisted of plain cervical spine $\mathrm{x}$-ray series, computerized tomography (CT) scanning, and magnetic resonance (MR) imaging. Computerized tomography myelograms were obtained in patients who could not tolerate MR imaging, as well as in difficult cases. 
Of these 25 patients, 14 were men. Twelve patients were younger than 60 years and 13 patients were older. The average symptom duration before the surgical procedure was 19 months (range 6-39 months). All patients underwent an expansive laminoplasty, and two of them underwent a concurrent facet fusion with cables and autograft for preoperatively demonstrated segmental instability. All patients wore a rigid cervical collar for 8 weeks postoperatively and plain radiographs were obtained in each one on postoperative Day 2. A CT scan was obtained in all patients and MR imaging was obtained in four by 8 weeks postoperatively, earlier when there were complaints referrable to the cervical spine. Cervical spine $\mathrm{x}$-ray series, including lateral flexion-extension views, were obtained 8 to 10 weeks postoperatively in all patients before the removal of the rigid collar. No further x-ray films were obtained unless new or recurrent symptoms were reported. A minimum of 18 months of follow-up review was available in all patients (range 18-43 months). The clinical status recorded on the most recent follow-up examination was compared to that of the preoperative assessment.

The spinal canal/vertebral body (SC/VB) ratio was taken from the preoperative CT scan at the level of the most severe stenosis. The lateral cross-compression ratio was taken from the same CT slice. These identical parameters were also obtained from postoperative CT scans of the same level.

\section{Operative Tecnique}

All procedures were performed in conjunction with somatosensory evoked potential (SSEP) and, if necessary, motor evoked potential (MEP) monitoring. The high-dose methylprednisolone protocol[2] and a course of perioperative intravenous antibiotic medications were used in all patients. The head and neck were positioned and then immobilized by a Mayfield three-point headholder. A standard midline incision was made to expose the spinous processes from C2-T1 for a typical C3-7 laminoplasty. After the subperiosteal dissection was completed, the interspinous ligaments at C2-3 and C7-T1 were removed. The spinous processes of $\mathrm{C} 3-7$ were resected near the junction with the lamina and a partial resection of the caudal C-2 spinous process was performed. After the C2-3 and C7-T1 interlaminar spaces were defined, the underlying ligamentum was removed using a combination of blunt and sharp dissections. Keyhole foraminotomies were performed as indicated. A drill with an AM-8 attachment (Midas Rex, Fort Worth, TX) was used to drill a gutter at the medial margin of the facet through the cancellous portion, but not through the inner cortex on the side of the open-door "hinge." A gutter on the contralateral side was similarly made, except that it penetrated the inner cortex and the canal (as in complete laminectomy). A small Kerrison rongeur was used to remove the underlying rim of ligamentum flavum. Using two angled curettes, the open side was slowly lifted. We generally opened the "door" on the more symptomatic side of the extremities. Any sublaminar adhesions were dissected free. A rib allograft soaking in antibiotic-containing saline was cut with the drill into appropriate lengths. The lengths of the grafts were then measured individually for the C-3, C-5, and C-7 laminectomy sites, which generally ranged from 12 to $18 \mathrm{~mm}$. A small trough was made on each end of the graft, so the graft could lodge securely on the lamina on one end and on the medial facet on the other end (Fig. 1). 


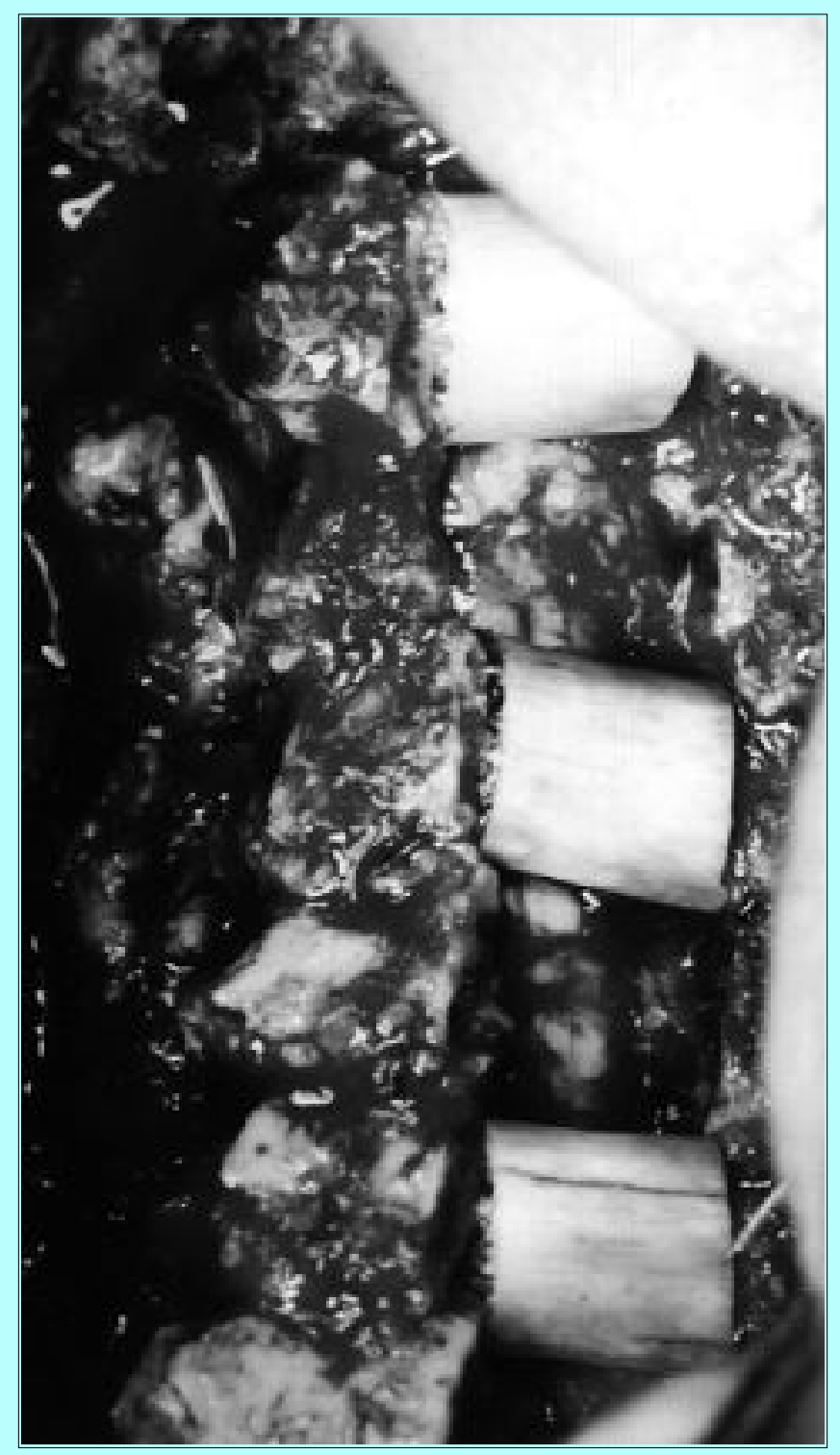

Fig. 1. Intraoperative photograph of a completed C3-7 expansive laminoplasty with rib allografts wedged at C-3, C-5, and C-7.

Autologous bone chips were used to fill the center of the cut rib allografts. After the grafts were placed and hemostasis was obtained, a drain was left in place and the wound was closed in layers in the usual fashion. No suture, cable, or screw was used unless a simultaneous posterior fusion was contemplated. The canal diameter restoration was generally excellent (Fig. 2). 


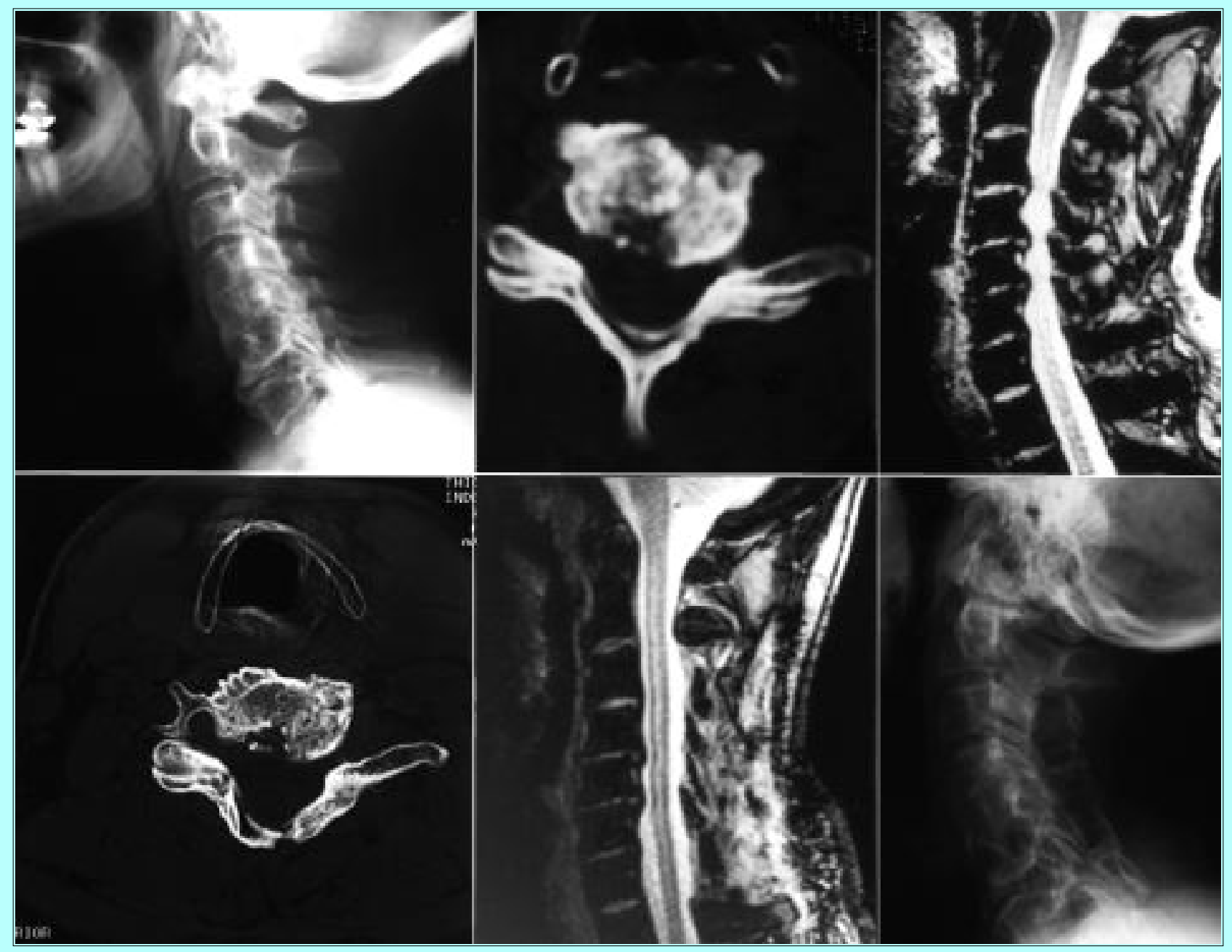

Fig. 2. Radiographic studies obtained in a 63-year-old man presenting with progessive myelopathy and right-hand numbness. Upper: Preoperative plain x-ray film (upper left) and computerized tomography (CT) scan (upper center) showing decreased canal diameter and spondylotic changes. A T2-weighted magnetic resonance (MR) image (upper right) displaying a narrowed subarachnoid space with mild myelomalacic changes. Lower: Postoperative CT scan (lower left) and MR image (lower center) demonstrating expansion of the cervical canal size. Lateral cervical spine x-ray (lower right) obtained 12 months after laminoplasty.

\section{RESULTS}

All 25 patients presented with progressive myelopathy and four (16\%) of them presented with signs and symptoms of radiculopathy. All patients presented with gait disturbance. When judged according to Nurick's[9] classification of disability in spondylotic myelopathy, the average preoperative grade was 2.76. The preoperative and postoperative grades of these 25 patients are shown in Table 1. 
TABLE 1

Prieoperiat NE AND POSTOPERATIVE NURICK'S DISABILTY GRADES IN 25 PATIENTS WITH CERYICAL SPONDVLOTK MVELOPATHY

\begin{tabular}{|c|c|c|c|c|c|c|c|}
\hline \multirow{2}{*}{$\begin{array}{c}\text { Time } \\
\text { of Assessment }\end{array}$} & \multicolumn{6}{|c|}{ Disability Grade (no. of pati ents) } & \multirow{2}{*}{$\begin{array}{c}\text { Awerage } \\
\text { Disability } \\
\text { Grade }\end{array}$} \\
\hline & 0 & I & II & III & IV & $V$ & \\
\hline $\begin{array}{l}\text { preop } \\
\text { postop }\end{array}$ & $\begin{array}{l}0 \\
2\end{array}$ & $\begin{array}{l}0 \\
9\end{array}$ & $\begin{array}{r}12 \\
8\end{array}$ & $\begin{array}{l}7 \\
4\end{array}$ & $\begin{array}{l}6 \\
2\end{array}$ & $\begin{array}{l}0 \\
0\end{array}$ & $\begin{array}{l}2.76 \\
1.80\end{array}$ \\
\hline
\end{tabular}

All patients had long-tract signs, which included Hoffmann, Babinski, clonus, hyperreflexia, and posterior column dysfunction (Table 2). Nondermatomal hand numbness and tingling were described by 15 patients (60\%). Upper-extremity weakness and nondermatomal pain were described by $14(56 \%)$ and seven $(28 \%)$ patients, respectively. Nonspecific lower-extremity weakness, numbness, and nondermatomal pain were identified in 14 (56\%), five (20\%), and five (20\%) patients, respectively. Bowel or bladder dysfunctions were reported by 13 patients (52\%) (Table 3). Clinical radiculopathy was diagnosed in four patients.

\begin{tabular}{|c|c|c|}
\hline \multicolumn{3}{|c|}{$\begin{array}{c}\text { TABLE } 2 \\
\text { PREOPERATME LONGTRACT SIGNS AND POSTOPERATIVE GAIT IMPROVEMENT IN } \\
25 \text { PATIENTS WITH CERVICAL SPONDVLOTK MVLOPATHY }\end{array}$} \\
\hline Long-Tract Sign & $\begin{array}{l}\text { No. of Patierts } \\
\text { With Preop Long- } \\
\text { Tract Sign }(\%)\end{array}$ & $\begin{array}{l}\text { No. of Patierts } \\
\text { With P'ostop Gait } \\
\text { Improvement }(\%)\end{array}$ \\
\hline $\begin{array}{l}\text { Hoffmann } \\
\text { Babinski } \\
\text { clonus } \\
\text { hyperreflexia } \\
\text { posterior colum n dysunction }\end{array}$ & $\begin{array}{l}14 \text { of } 25(56) \\
16 \text { of } 25(64) \\
13 \text { of } 25(52) \\
12 \text { of } 25(48) \\
8 \text { of } 25(32)\end{array}$ & $\begin{array}{c}13 \text { of } 14(93) \\
14 \text { of } 16(88) \\
12 \text { of } 13(92) \\
10 \text { of } 12(83) \\
6 \text { of } 8(75)\end{array}$ \\
\hline
\end{tabular}

Intraoperative SSEP signals improved in five (20\%) of the 25 patients and all five of these patients experienced gait improvement at follow-up examination. Nerve root irritation documented by electromyelographic monitoring was seen in two of the four patients undergoing foraminotomes. We generally stop decompression under this circumstance and wait until these signal patterns return to normal spontaneously. No discernible loss of motor function was found postoperatively. 


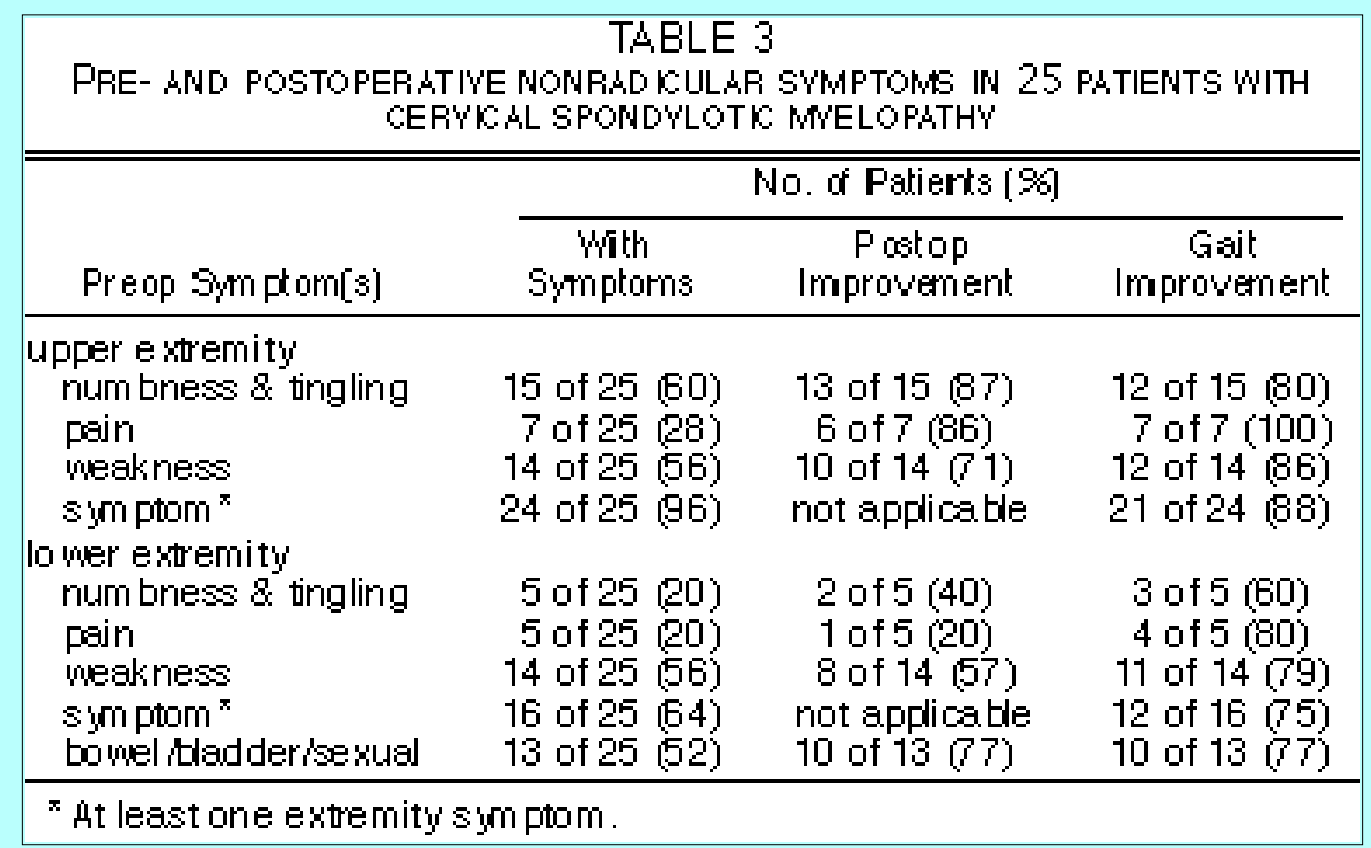

Postoperatively, gait disturbance was improved in $21(84 \%)$ of 25 patients at the time of the most recent follow-up evaluation. The average disability grade was improved to 1.8 (Table 1). When compared to the preoperative disability grade of 2.76 using the two-tailed t-test, the alpha was less than 0.05 .

Nondermatomal hand numbness and tingling were improved in $13(87 \%)$ of 15 patients. Bowel, bladder, and/or sexual dysfunctions were improved in 10 (77\%) of 13 patients. Radiculopathy was alleviated in all four patients.

The ratio of the mean midline anteroposterior diameter of the $\mathrm{SC}$ to the $\mathrm{VB}$ was used to define the degree of stenosis. Measurement of the preoperative radiographic studies yielded an SC/VB ratio of 0.632 . Postoperative imaging studies demonstrated an SC/VB ratio of 0.871 . When the SC/VB ratios were compared using the two-tailed t-test, the alpha was less than 0.001 . The average compression ratio (sagittal diameter/transverse diameter X 100\%) was 37\% preoperatively and 63\% postoperatively. When the compression ratios were compared using the two-tailed t-test, the alpha was less than 0.005 .

Surgical outcome (defined in terms of gait improvement) with respect to the various preoperative predictors was analyzed. The presence of various long-tract signs did not appear to affect the surgical outcome in our patient population (Table 1). All patients younger than 60 years of age at the time of presentation demonstrated postoperative gait improvement. In contrast, only $67 \%$ of the patients older than 60 years showed gait improvement. Patients with lower-extremity dysfunction showed less gait improvement than patients with upper-extremity dysfunction (75\% vs. 88\%) (Table 3). Thirteen patients presented with symptom durations longer than 18 months and only $10(77 \%)$ of them demonstrated gait improvement, whereas 11 (92\%) of 12 patients with symptomatology lasting less than 18 months improved on their postoperative gait assessment. Only $10(77 \%)$ of 13 patients with preoperative bowel or bladder dysfunction had a favorable outcome, although $11(92 \%)$ of 12 patients without such a dysfunction showed improvement. Preoperative spinal cord signal change was observed on MR imaging in 10 patients and eight (80\%) showed gait improvement. The men had an 86\% (12 of 14) gait improvement rate and the women had an $82 \%$ (nine of 11) rate of postoperative gait improvement. None of the aforementioned parameters reached statistical significance according to the chi-square analysis with Yate's correction, given the relatively small population size of 25 patients. In general, this procedure alleviated upper-extremity symptoms more than lower-extremity symptoms (Table 3). 
One complication was seen in this group of patients: a patient who presented with anterior scalene/thoracic outlet compression syndrome postoperatively, with signs of brachial plexopathy (rotator cuff, brachioradialis, and hand intrinsic muscle hypotrophy of the hand) and diminished pulse on arm abduction. Repeated plain X-ray films, MR imaging, and CT scans did not demonstrate a cause, but an electromyelograph revealed possible nerve root impingement. The patient's medical history was further complicated by a diagnosis of ulnar entrapment which was treated with an ulnar nerve transposition. He subsequently underwent a surgical exploration, with excision of some middle scalene muscle bands under the lower trunk. His symptoms, however, remained the same 4 months after the excision of scalene medius. We were not certain how the procedure led to this syndrome postlaminoplasty.

No cerebrospinal fluid leak, graft dislodgement, or C-5 nerve root dysfunction was identified in this group of patients. No instability or kyphotic deformity was observed on the lateral flexion-extension cervical spine $\mathrm{x}$-ray films 8 to 10 weeks postoperatively. X-ray films were obtained in five patients 6 to 30 months postoperatively, but similarly did not show kyphotic deformity.

\section{DISCUSSION}

Posterior cervical decompression has been accepted as the treatment of choice for cervical canal stenosis caused by OPLL.[6] It is also the procedure of choice when patients present with multilevel canal stenosis caused by spondylotic changes.[4,12] We treated 25 patients with cervical spondylotic myelopathy and found $84 \%$ (21 patients) to have improved in gait postoperatively. Most patients with bowel or bladder dysfunction also experienced improvement of their sphincter function. Longer periods of follow-up review would be needed to evaluate the long-term outcome from these procedures. The canal diameter was greatly increased by this procedure. Minimal complication was encountered. We did not encounter patients with C-5 nerve root injury,[13] cerebrospinal fluid leak, or graft dislodgement in this series of patients, three of the more frequent complications that arise from a cervical decompression procedure. One patient from this group experienced an anterior scalene syndrome postoperatively; this patient was first managed conservatively and then treated surgically. His symptoms did not change significantly after the second operation. In general, we have found open-door laminoplasty to be a safe and effective method to alleviate symptoms from spondylotic myelopathy.

It had been suggested that preoperative lower-extremity weakness and sphincter dysfunctions were associated with poorer surgical outcome.[4] We investigated the role of predictors for outcome, which include age, gender, preoperative upper- and lower-extremity dysfunction, presence of various long tract signs, preoperative cord signal abnormality, and duration of symptoms. We found that duration of symptoms for more than 18 months, age greater than 60 years at the time of presentation, bowel or bladder dysfunction, and lower-extremity dysfunction (weakness, numbness, tingling, and nondermatomal pain) were associated with poorer postoperative gait improvement. None of these predictors, however, reached statistical significance according to the chi-square analysis because of the relatively small population size. Even in patients having the negative predictors described above, more than $70 \%$ experienced postoperative improvement in gait. Preoperative spinal cord signal change did not affect surgical outcome in our series, which was similarly reported in the past.[8]

\section{References}

1. Bohlman HH: Cervical spondylosis with moderate to severe myelopathy. A report of seventeen cases treated by Robinson anterior cervical discectomy and fusion. Spine 2:151-162, 1977 
2. Bracken MB, Shepard MJ, Collins WF, et al: A randomized, controlled trial of methylprednisolone or maloxone in the treatment of acute spinal-cord injury. Results of the Second National Acute Spinal Cord Injury study. N Engl J Med 322:1405-1411, 1990

3. Clarke E, Robinson PK: Cervical myelopathy: a complication of cervical spondylosis. Brain 79:483-498, 1956

4. Crandall PH, Gregorius FK: Long-term followup of surgical treatment of cervical spondylotic myelopathy. Spine 2:139-146, 1977

5. Epstein JA: The surgical management of cervical spinal stenosis, spondylosis and myeloradiculopathy by means of the posterior approach. Spine 13:864-869, 1988

6. Epstein $\mathrm{N}$ : The surgical management of ossification of the posterior longitudinal ligament in 51 patients. J Spine Disord 6:432-455, 1993

7. Hirabayashi K, Satomi K: Operative procedure and results of expansive open-door laminoplasty. Spine 13:870-876, 1988

8. Morio Y, Yamamoto K, Kuranobu K, et al: Does increased signal intensity of the spinal cord on MR images due to cervical myelopathy predict prognosis? Arch Orthop Trauma Surg 113:254-259, 1994

9. Nurick S: The pathogenesis of the spinal cord disorder associated with cervical spondylosis. Brain 95:87-100, 1972

10. Oyama M, Hattori S, Moriwaki N: A new method of cervical laminoplasty. Cent Jpn J Orthop Traumat Surg 16:792-794, 1973

11. Saito T, Yamamuro T, Shikata J, et al: Analysis and prevention of spinal column deformity following cervical laminectomy. I. Pathogenetic analysis of postlaminectomy deformities. Spine 16:494-502, 1991

12. Satomi K, Nishu Y, Kohno T, et al: Long-term follow-up studies of open-door expansive laminoplasty for cervical stenotic myelopathy. Spine 19:507-510, 1994

13. Saunders RL: On the pathogenesis of the radiculopathy complicating multilevel corpectomy. Neurosurgery 37:408-413, 1995

14. White AA III, and Panjabi MM: Biomechanical considerations in the surgical management of cervical spondylotic myelopathy. Spine 13:856-860, 1988

15. Whitecloud TS III: Anterior surgery for cervical spondylotic myelopathy. Smith-Robinson, Cloward, and vertebrectomy. Spine 13:861-863, 1988

16. Yonenobu K, Fuji T, Ono K, et al: Choice of surgical treatment for multisegmental cervical spondylotic myelopathy. Spine 10:710-716, 1985

17. Yonenobu K, Hosono N, Iwasaki M, et al: Laminoplasty versus subtotal corpectomy. A comparative study of results in multisegmental cervical spondylotic myelopathy. Spine 17:1281-1284, 1992

Manuscript received February 8, 1996. 
Accepted in final form August 7, 1996.

Address reprint requests to: Thomas T. Lee, M.D., Department of Neurological Surgery, University of Miami School of Medicine, P.O. Box 016960 (M813), Miami, Florida 33101. 